Article

\title{
Tumor Cell-Derived Microvesicles Induced Not Epithelial-Mesenchymal Transition but Apoptosis in Human Proximal Tubular (HK-2) Cells: Implications for Renal Impairment in Multiple Myeloma
}

\author{
Aiqi Zhao ${ }^{1,{ }^{\dagger}}$, Fancong Kong ${ }^{1,2,+}$, Chun-Jie Liu ${ }^{3}$, Guoxin Yan ${ }^{1}$, Fei Gao ${ }^{1}$, Hao Guo ${ }^{1}$, \\ An-Yuan Guo ${ }^{3}$, Zhichao Chen ${ }^{1, *}$ and Qiubai Li ${ }^{1, *}$ \\ 1 Institute of Hematology, Union Hospital, Tongji Medical College, Huazhong University of Science and \\ Technology, Wuhan 430022, China; zhao_aiqi@163.com (A.Z.); konglinda212@163.com (F.K.); \\ dysrmygx@sina.com (G.Y.); gaof@hust.edu.cn (F.G.); gh273397674@163.com (H.G.) \\ 2 Department of Hematology, The First Affiliated Hospital of Nanchang University, Nanchang 330000, China \\ 3 Hubei Bioinformatics \& Molecular Imaging Key Laboratory, Department of Bioinformatics and Systems \\ Biology, Key Laboratory of Molecular Biophysics of the Ministry of Education, College of Life Science and \\ Technology, Huazhong University of Science and Technology, Wuhan 430074, China; \\ samliu@hust.edu.cn (C.-J.L.); guoay@hust.edu.cn (A.-Y.G.) \\ * Correspondence: zhichaochen@hust.edu.cn (Z.C.); qiubaili@hust.edu.cn (Q.L.); \\ Tel./Fax: +86-27-8572-6387 (Q.L.) \\ + These authors contributed equally to this study.
}

Academic Editors: Thomas Ritter, Matthew Griffin and Aideen Ryan

Received: 4 December 2016; Accepted: 21 February 2017; Published: 27 February 2017

\begin{abstract}
Renal impairment (RI) is one of the hallmarks of multiple myeloma (MM) and carries a poor prognosis. Microvesicles (MVs) are membrane vesicles and play an important role in disease progression. Here, we investigated the role of MVs derived from MM cells (MM-MVs) in RI of MM. We found that MM-MVs significantly inhibited viability and induced apoptosis, but not epithelial-mesenchymal transition in human kidney-2 (HK-2), a human renal tubular epithelial cell line. The protein levels of cleaved caspase-3, 8, and 9, and E-cadherin, were increased, but vementin levels were decreased in the HK-2 cells treated with MM-MVs. Through a comparative sequencing and analysis of RNA content between the MVs from RPMI8226 MM cells (RPMI8226-MVs) and K562 leukemia cells, RPMI8226-MVs were enriched with more renal-pathogenic miRNAs, in which the selective miRNAs may participate in the up-regulation of the levels of cleaved caspase-3. Furthermore, the levels of CD138+ circulating MVs (cirMVs) in the peripheral blood were positively correlated with the severity of RI in newly-diagnosed MM. Our study supports MM-MVs representing a previously undescribed factor and playing a potential role in the development of RI of MM patients, and sheds light on the potential application of CD138+ cirMV counts in precise diagnosis of RI in $\mathrm{MM}$ and exploring MM-MVs as a therapeutic target.
\end{abstract}

Keywords: microvesicles; multiple myeloma; renal impairment

\section{Introduction}

Kidney damage from multiple myeloma (MM) is a cause of renal impairment (RI) in patients with MM and a hallmark of MM. As one of the most common complications of MM, RI presents in $20 \% \sim 25 \%$ of newly-diagnosed patients [1-3] and more than $50 \%$ of advanced disease [4], and carries a poor prognosis [4-6]. 
In RI of MM patients, cast nephropathy is the most common kind of kidney damage. The characteristic renal lesion is a chronic tubulointerstitial nephropathy with marked tubular atrophy and laminated intratubular casts, which was caused by the proximal tubular endocytosis of immunoglobulin light chains [7]. However, in spite of the use of novel drugs to treat MM and novel treatment to treat RI, the results of these treatments to prevent or reverse myeloma nephropathy have been disappointing in some patients [8]. Studies to reveal the novel mechanisms underlying RI of MM patients are urgently needed.

A growing body of studies have confirmed microvesicles (MVs) to play an important role in the interactions between different cells [9]. These tiny particles present a wide range of sizes (100-1000 nm in diameter), are composed of a selection of proteins, lipids, and nucleic acids [10], and have been involved into numerous pathogenic processing of cancer development, such as proliferation, metastasis, angiogenesis, and immunity [11-13]. Our previous studies have confirmed the presence of MM-MVs and demonstrated their role in MM-related angiogenesis and tumor cell proliferation [11,14], but it remains unknown about their role in RI of MM. Thus, in the present study, we used MM-MVs to treat human proximal tubular (human kidney-2, HK-2) cells to observe their changes in proliferation, apoptosis, and epithelial-mesenchymal transition (EMT) in vitro, and clinically investigated the associations between peripheral circulating CD138+ cirMV counts and severity of RI in patients with MM.

\section{Results}

\subsection{Validation and Characteristics of Myeloma Cell-Derived Microvesicles ( MM-MVs)}

MVs derived from MM cells were acquired and validated as previously described [11,14]. As shown in Figure 1A,B, under a transmission electron microscopy (TEM), U266 MM cells were surrounded by lipid-bilayer vesicles shaping the outlines of smooth curved surfaces, and in various sizes, between 100-1000 nm in diameter. Meanwhile, observed by scanning electron microscopy (SEM), multitudinous diverse spheroid shapes, with diameters in the range of 100-1000 nm, were decorated on the RPMI8226 cell surface (Figure 1C). Furthermore, the MM-MVs derived from U266 cells (U266-MVs) and from RPMI8226 cells (RPMI8226-MVs) were analyzed using flow cytometry. As we previously described, these MM-MVs were determined to express Calcein-AM and CD138 (Figure 1D,E).

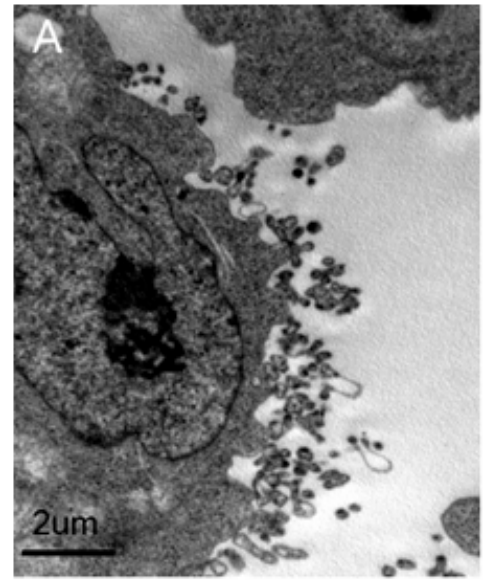

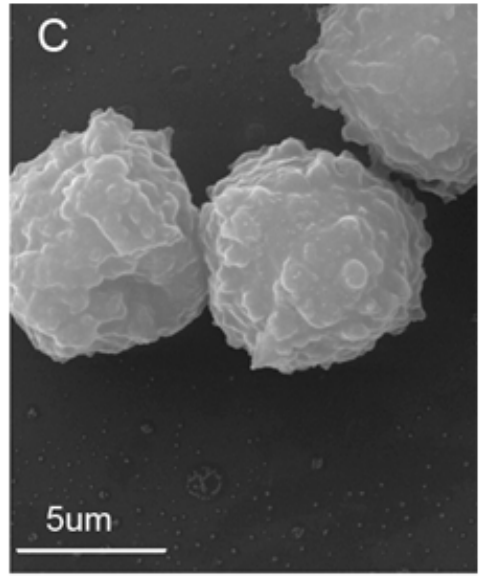

Figure 1. Cont. 


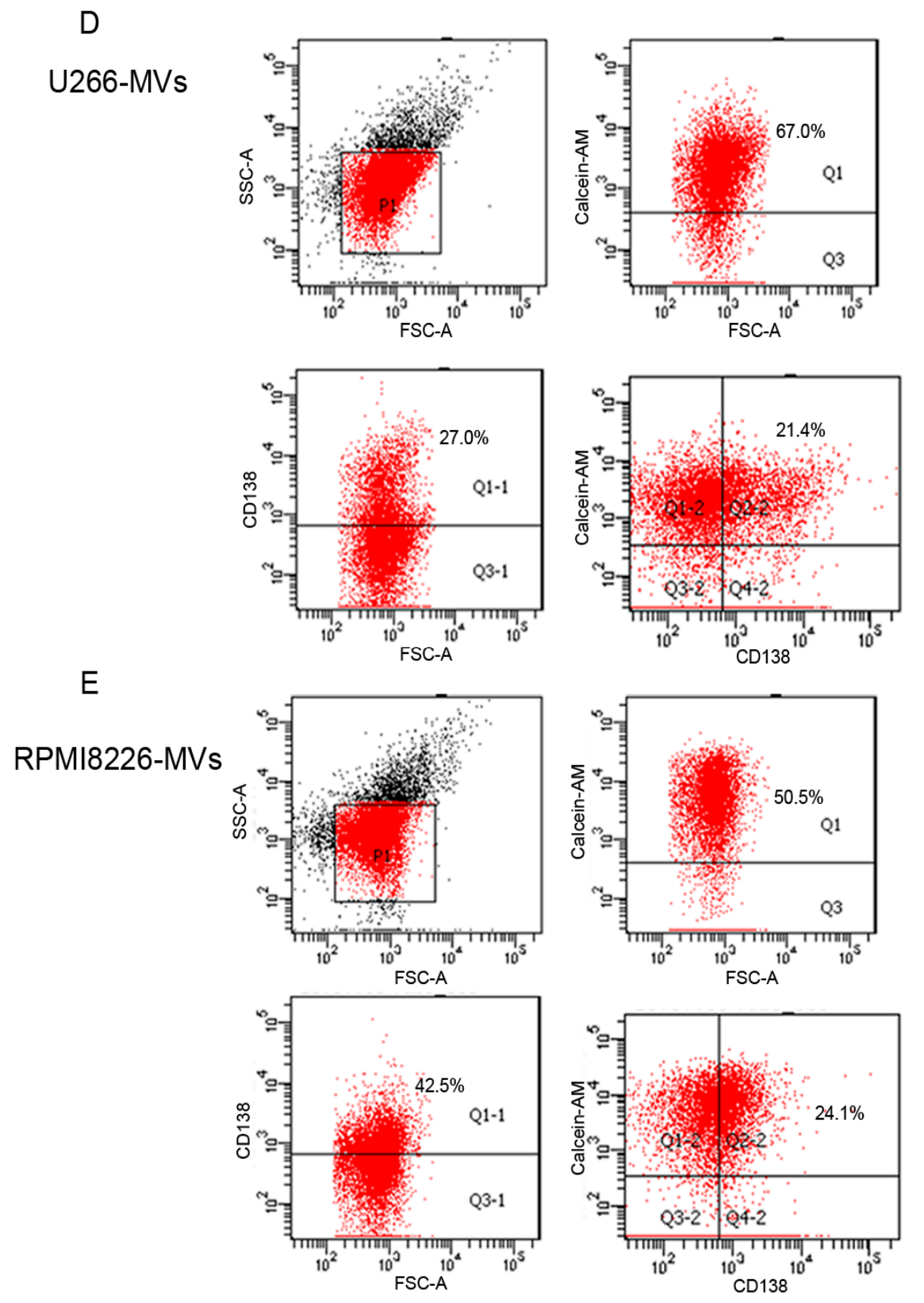

Figure 1. Characterization of myeloma cell-derived microvesicles (MM-MVs) (A,B) Transmission electron microscopy revealing MVs (arrow) as 100-1000 $\mu \mathrm{m}$ vesicles shed from U266 cells (U266-MVs). Scale bar $=2 \mu \mathrm{m}$ (A) and $0.2 \mu \mathrm{m}$ (B); (C) Scanning electron microscopy showing typical morphology of MVs derived from RPMI8226 myeloma cells (RPMI8226-MVs). Scale bar $=2 \mu \mathrm{m}$; (D,E) Representative flow cytometry analysis of U266-MVs and RPMI8226-MVs revealing the presence of CD138+Calcein-AM+ vesicles, with the $1 \mu \mathrm{m}$ microbeads for gating the MVs for size verification and Calcein-AM to detect the integrity of MVs.

\subsection{MM-MVs Inhibit Viability and Induce Apoptosis in Human Kidney-2 Cells (HK-2 Cells)}

Severe acute kidney injury is very common in RI of MM (MM-RI) [3], and renal repair is dependent on tubular regeneration. To test whether MM-MVs might be involved into the development of MM-RI, we used MM-MVs to treat HK-2, a human proximal tubular cell line, and observed the changes in viability, apoptosis, and morphology in HK-2 cells. For analysis of cell viability, HK-2 cells $\left(10^{5} / \mathrm{mL}\right)$ were cultured and treated with various concentrations of MM-MVs $(0,1,5,10$, and $50 \mu \mathrm{g} / \mathrm{mL})$ for 24,48 , and $72 \mathrm{~h}$, respectively. We found that optical density (OD) values in HK-2 cells significantly 
decreased, after treatment of various concentrations of RPMI8226-MVs within $48 \mathrm{~h}$ in a dose-dependent manner (vs. control, $p<0.05$ ). After $72 \mathrm{~h}$, the decrease was significant in HK-2 cells treated with $50 \mu \mathrm{g} / \mathrm{mL}$ of RPMI8226-MVs, but not in the other groups (Figure 2A). In HK-2 cells treated with U266-MVs, the changes in OD value detected were similar to those in RPMI8226-MV-treated cells. However, MVs derived from K562 cells (K562-MVs), a human leukemia cell line, failed to exhibit this inhibitory effect (Figure 2A). Additionally, to exclude the possible effect of the mixed cytokines in the MV samples, we compared the effect of MM RPMI 8226 and U266 cell medium with and without the depletion of MV on the viability and apoptosis of HK-2 cells, respectively. No significant difference could be found between the two groups, suggested the mild effect of cytokines in the medium on the viability and apoptosis of HK-2 cells (Supplementary Figure S1).These results suggest that various concentrations of MM-MVs can significantly inhibit the viability in HK-2 cells, while this inhibitory effect reach to the utmost limit at $72 \mathrm{~h}$ even with the treatment of MM-MVs at $50 \mu \mathrm{g} / \mathrm{mL}$ (Figure 2A).

We next investigated the changes in apoptosis in HK-2 cells treated with various concentrations of MM-MVs at $48 \mathrm{~h}$. It was shown that both types of MM-MVs significantly induced apoptosis in HK-2 cells in a dose-dependent manner (Figure 2B). Meanwhile, no obvious changes were observed in the HK-2 cells treated with various concentrations of K562-MVs (Figure 2B). These findings support that MM-MVs can induce apoptosis in HK-2 cells.

It has been reported that EMT plays an important role in tubulointerstitial renal fibrosis in MM [15]. Therefore, we observed the effect of MM-MVs on the morphology of the HK-2 cells treated with MM-MVs or K562-MVs ( $50 \mu \mathrm{g} / \mathrm{mL}$ ) using an charge-coupled Nikon Coolpix 995 digital charge-coupled device (CCD) camera attached to a Nikon Diaphot inverted phase-contrast microscope (Nikon, Tokyo, Japan). As shown in Figure 2C, no distinct elongation/filopodia formation was found. This finding primarily suggests that MM-MVs did not induce EMT in the HK-2 cells.

\section{A}

HK-2 treated with RPMI8226-MVs
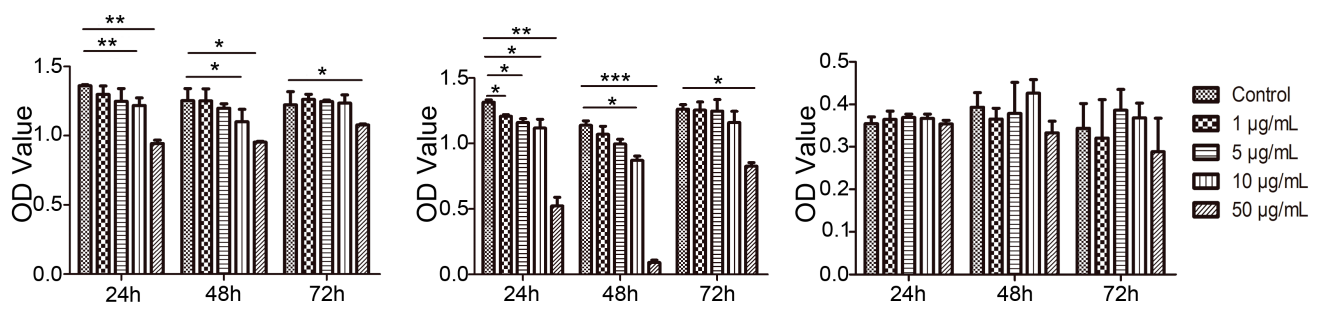

B

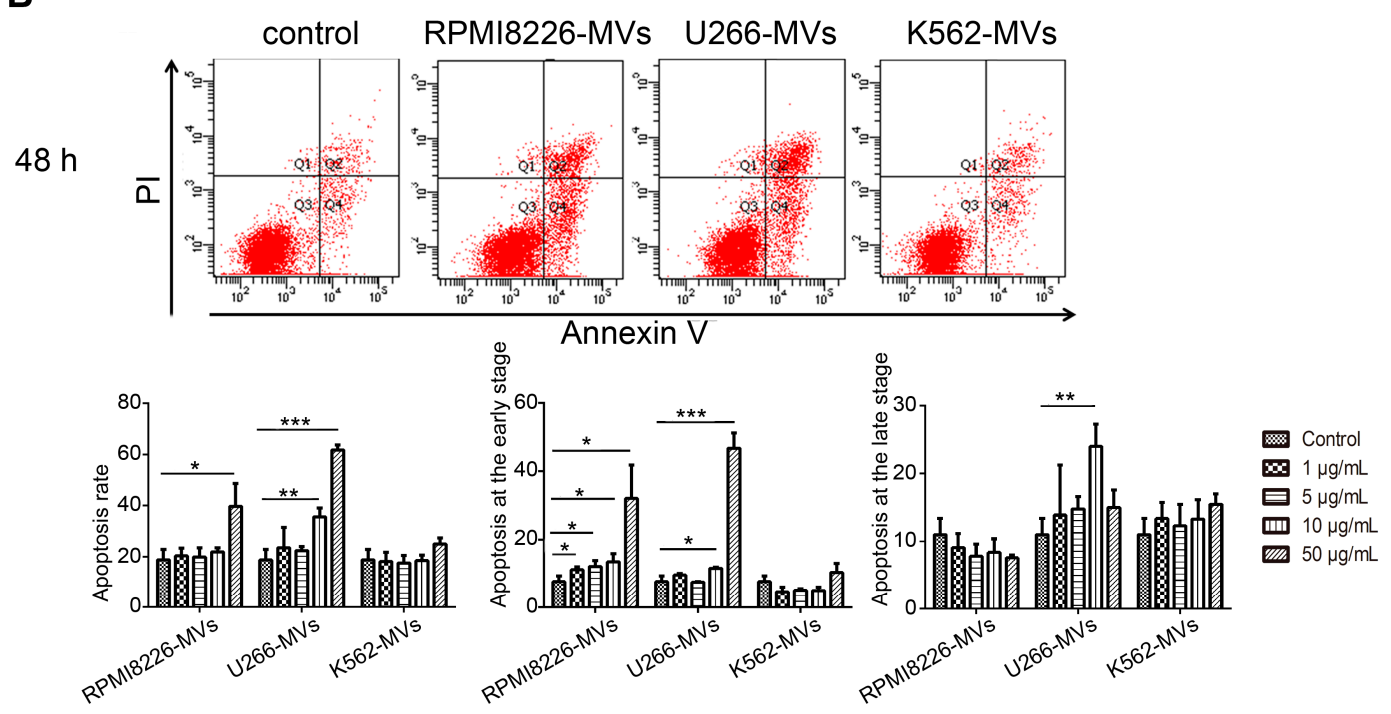

Figure 2. Cont. 


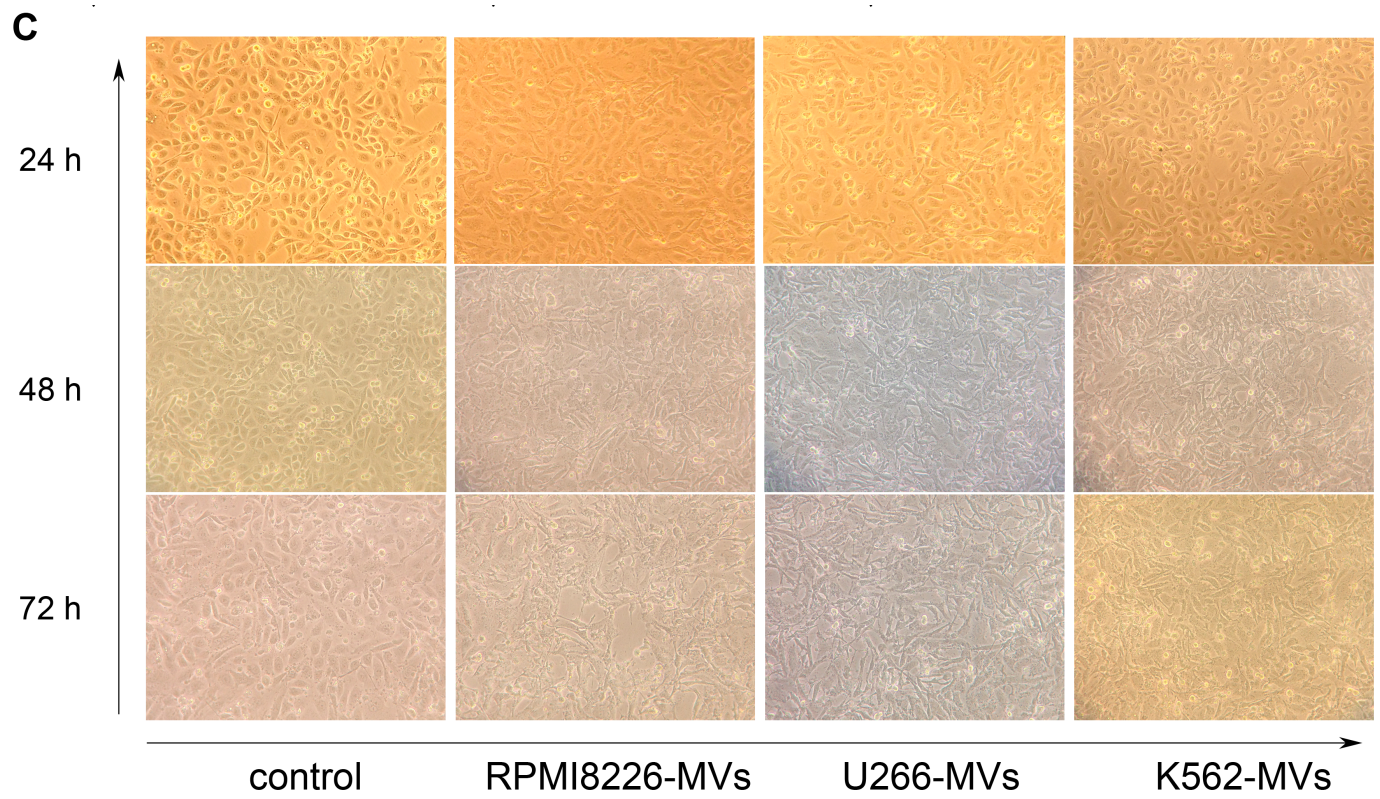

Figure 2. Inhibited viability and induced apoptosis in human kidney-2 cells (HK-2 cells) by MM-MVs. (A) HK-2 cells $\left(10^{5} / \mathrm{mL}\right)$ were treated with various concentrations of MM-MVs and K562-MVs $(1,5,10$, and $50 \mu \mathrm{g} / \mathrm{mL})$ for 24,48 , and $72 \mathrm{~h}$, respectively. The effects of MM-MVs on viability in HK-2 cells were determined with Cell Counting Kit-8 (CCK-8) assay. MM-MVs, but not K562-MVs, inhibited proliferation in HK-2 cells at the time points in a dose-dependent manner; (B) After $48 \mathrm{~h}$, the effects of MM-MVs and K562-MVs on apoptosis in HK-2 cells were determined with FITC-annexin V-PI FCM analysis. MM-MVs, but not K562-MVs, induced apoptosis in HK-2 cells at $48 \mathrm{~h}$ in a dose-dependent manner. Representative FCM analysis of early and late apoptosis in HK-2 cells treated with MM-MVs and K562-MVs (10 $\mu \mathrm{g} / \mathrm{mL})$ (top) and bar graphs for apoptosis rates (bottom); (C) The effects of MM-MVs on the morphology of the HK-2 cells treated with MM-MVs or K562-MVs $(50 \mu \mathrm{g} / \mathrm{mL})$ were observed using an charge-coupled Nikon Coolpix 995 digital charge-coupled device (CCD) camera attached to a Nikon Diaphot inverted phase-contrast microscope (Nikon, Tokyo, Japan), Magnification: $100 \times .{ }^{*} p<0.05,{ }^{* *} p<0.01,{ }^{* * *} p<0.001$.

\subsection{MM-MVs Activate Apoptic Pathways of Caspase-3, $-8,-9$ and Bcl-2 Family Members}

Based on the evident apoptosis in the HK-2 cells treated with MM-MVs, we next checked whether caspases, the key regulators of cell apoptosis, were involved in the induced effect. Additionally, as the essential regulators in caspase-mediated intrinsic apoptisis pathway, Bcl-2 family members, such as Bim, Bcl-xl, Bid, tBid, and Bcl-2, were investigated by Western blot.

HK-2 cells were incubated with different types of MVs at the concentration of $10 \mu \mathrm{g} / \mathrm{mL}$ for 48 or $72 \mathrm{~h}$ and the protein levels of caspase-3/8/9 and Bcl-2 family members were assayed. As shown in Figure 3A,C, both at 48 and $72 \mathrm{~h}$, the cleaved caspase-3/8/9 levels were significantly up-regulated while their total caspase levels were down-regulated in both MM-MV groups, compared to the control and K562-MV group. Meanwhile, MM-MV treatment up-regulated the pro-apoptotic proteins (Bim and Bid) and down-regulated the anti-apoptotic proteins (Bcl-xl and Bcl-2) (Figure 3B,D). These results further evidence the MM-MV-induced apoptosis in HK-2 cells, which is possibly mediated by the mitochondrial-initiated intrinsic apoptotic pathways. 


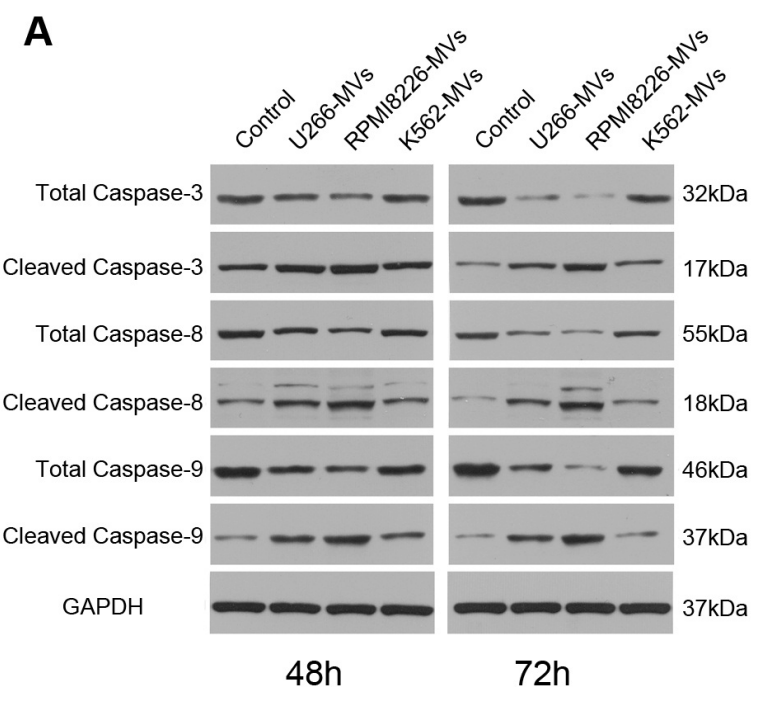

C

\section{$48 h$}

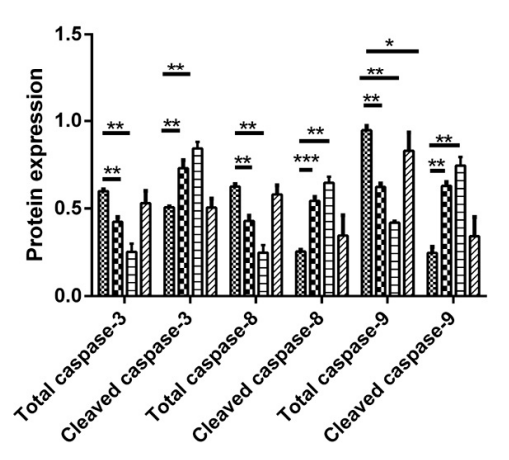

D

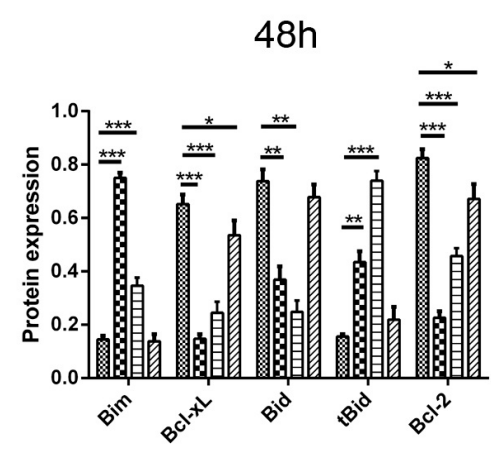

B

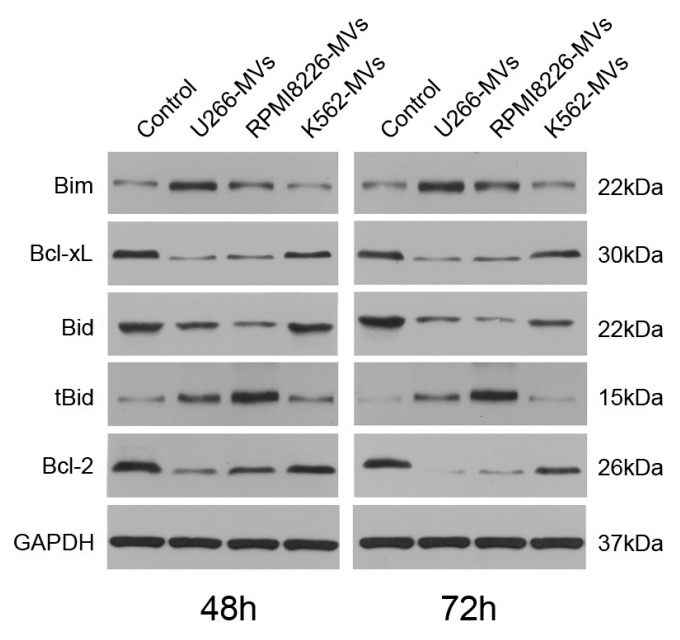

$72 \mathrm{~h}$

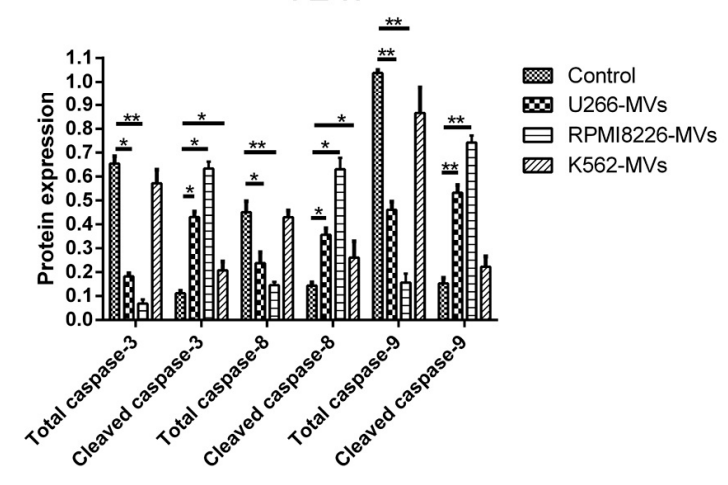

$72 \mathrm{~h}$

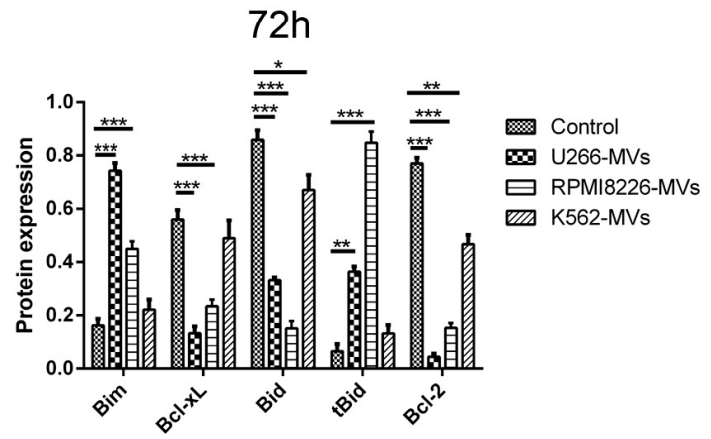

Figure 3. Activated apoptotic pathways of caspase-3, -8 , and -9 and Bcl-2 family members in HK-2 cells treated with MM-MVs. HK-2 cells were treated with MM-MVs and K562-MVs $(10 \mu \mathrm{g} / \mathrm{mL})$ and the expression of proteins was assayed by Western blotting. (A,C) MM-MVs, but not K562-MVs, significantly induced the activation of caspase-3, -8, and -9. Both U266-MVs and RPMI8226-MVs reduced the expression of total caspase-3, -8 , and -9 , and increased the expression of cleaved caspase-3, -8 , and -9; (B,D) MM-MVs up-regulated pro-apoptotic Bim and tBid proteins and down-regulated anti-apoptotic Bcl-xL and Bcl-2 proteins. Bar graphs for $(\mathbf{A}, \mathbf{B})$ were shown in $(\mathbf{C}, \mathbf{D})$, respectively. Each value was expressed as mean $\pm \mathrm{SD}$ of three independent experiments. ${ }^{*} p<0.05,{ }^{* *} p<0.01$, *** $p<0.001$ vs. control. 2.4. MM-MVs up-regulate E-cadherin protein and down-regulate vimentin protein in HK-2 cells. 


\subsection{MM-MVs Up-Regulate E-Cadherin Protein and Down-Regulate Vimentin Protein in HK-2 Cells}

To further study whether EMT was initiated in the MM-MV-treated HK-2 cells, HK-2 cells were incubated with different types of MVs at the concentration of $10 \mu \mathrm{g} / \mathrm{mL}$ for 48 or $72 \mathrm{~h}$, and the changes in EMT markers of E-cadherin and vimentin were assayed using Western blot and immunofluorescence. As shown in Figure 4A-D, both at 48 and $72 \mathrm{~h}$, MM-MVs significantly up-regulated E-cadherin levels and down-regulated vimentin levels in HK-2 cells, compared to the control and K562-MV group. However, K562-MVs showed no obvious effect on these EMT markers. Meanwhile, these findings were confirmed by immunofluorescence with staining of the primary antibodies (anti-E-cadherin and anti-vimentin, Figure 4E). Taken together, these findings confirm that MM-MVs can induce apoptosis, but not EMT in HK-2 cells.

A

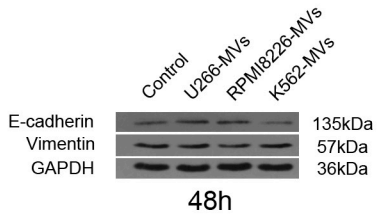

C $48 h$

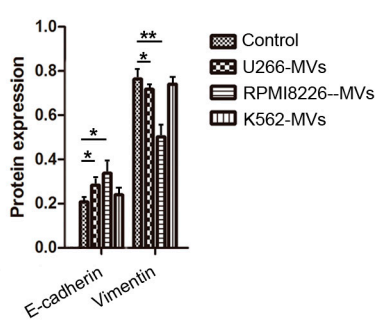

E

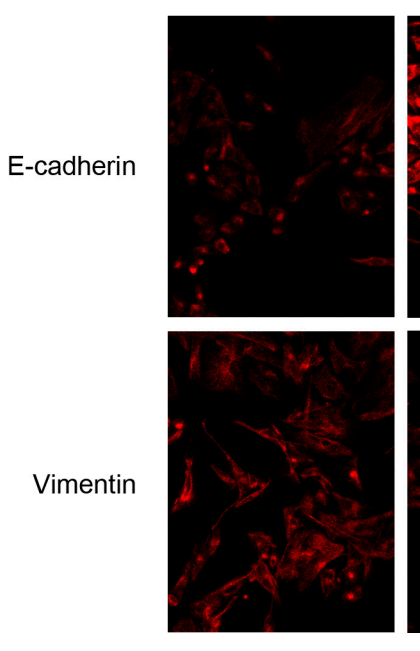

Control
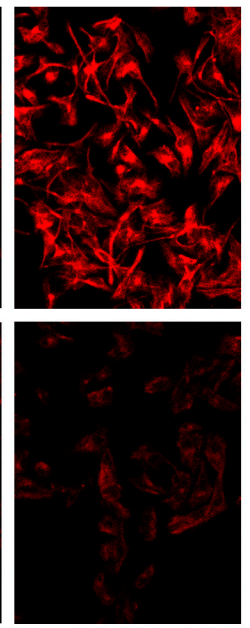

U266-MVs
B

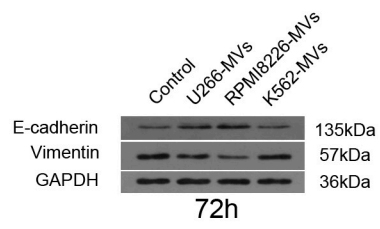

D $72 \mathrm{~h}$
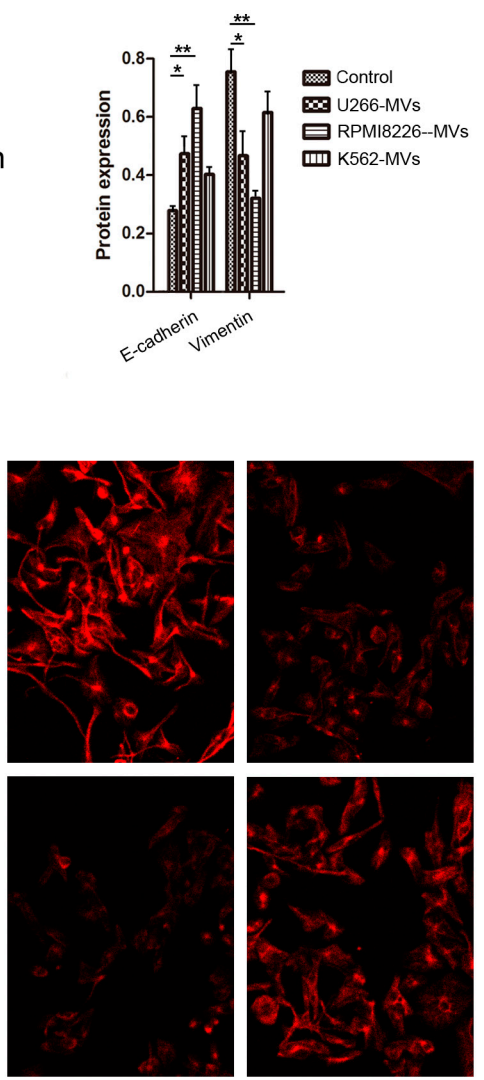

RPMI8226-MVs

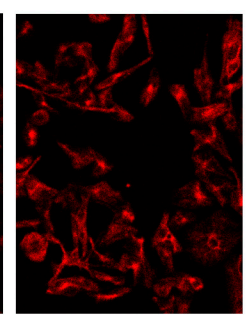

K562-MVs

Figure 4. MM-MVs up-regulate E-cadherin protein and down-regulate vimentin protein in HK-2 cells. HK-2 cells were treated with MM-MVs and K562-MVs $(10 \mu \mathrm{g} / \mathrm{mL})$ and the expression of proteins was assayed using Western blot and immnofluorescence analysis. MM-MVs, but not K562-MVs, significantly up-regulated E-caderin protein and down-regulated vimentin protein in the HK-2 cells at 48 (A) and $72 \mathrm{~h}$ (B). Bar graphs for A and B were shown in (C) and (D), respectively. The two EMT markers were also assayed using a Nikon (Melvile, NY, USA) Eclipse TE300 fluorescence microscope in the HK-2 cells treated with MM-MVs and K562-MVs $(10 \mu \mathrm{g} / \mathrm{mL})$ for $72 \mathrm{~h}(\mathrm{E})$ magnification, $200 \times$. Each value was expressed as the mean \pm SD of three independent experiments. ${ }^{*} p<0.05,{ }^{* *} p<0.01$ vs. control. 


\subsection{Selective miRNAs in MM-MVs that Confer Caspase-3-Induced Apoptosis in HK-2 Cells}

As miRNAs are selectively excreted into MVs and act as the core elements for tumor cells [16], we next investigated the signature of miRNA repertoires in MM-MVs. Firstly, we performed small RNA-Seq analysis and focused on the expression of RI-related miRNAs. Intriguingly, the comparison of signature in RPMI8266-MVs and K562-MVs revealed the particular enrichment of these miRNAs. As shown in Figure 5A,B, several RI-related miRNAs (for example, miR-20a, miR-92a, miR-17, miR-19a, miR-18a, and miR-17) that had been ascertained in the published literature [17-19], were significantly highly represented in RPMI8266-MVs than in K562-MVs. In contrast, the documented renal-protective miRNAs, such as let-7b, miR-16, miR-25, and miR-29 family [20-22], were at extremely lower levels in both RPMI8226-MVs and K562-MVs. These results raised the possibility that a significant proportion of renal pathogenic miRNAs were selectively sorted into MM-MVs, consistent with a low expression of protective miRNAs. The signature of miRNA abundance might provide the role of secreted miRNAs in the inhibited viability and induced apoptosis in the HK-2 cells caused by MM-MVs.

A

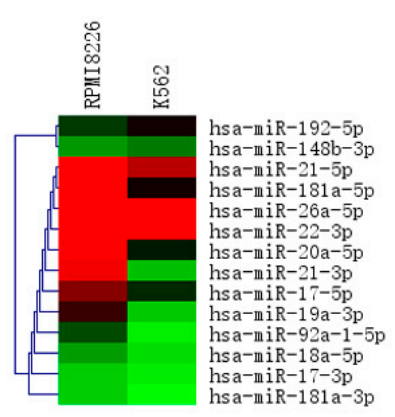

B

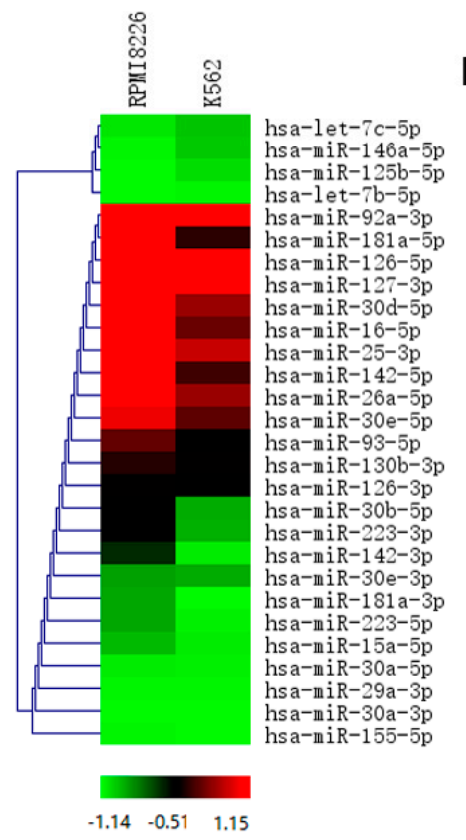

C

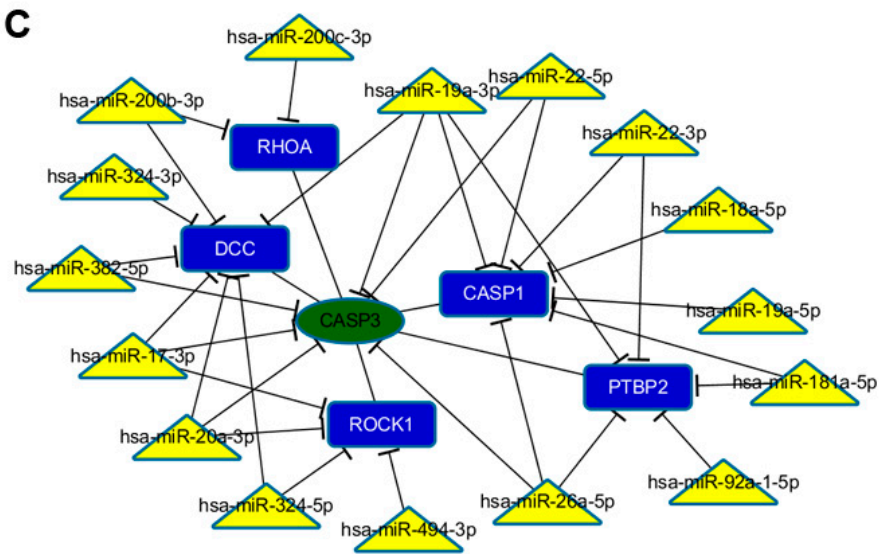

D

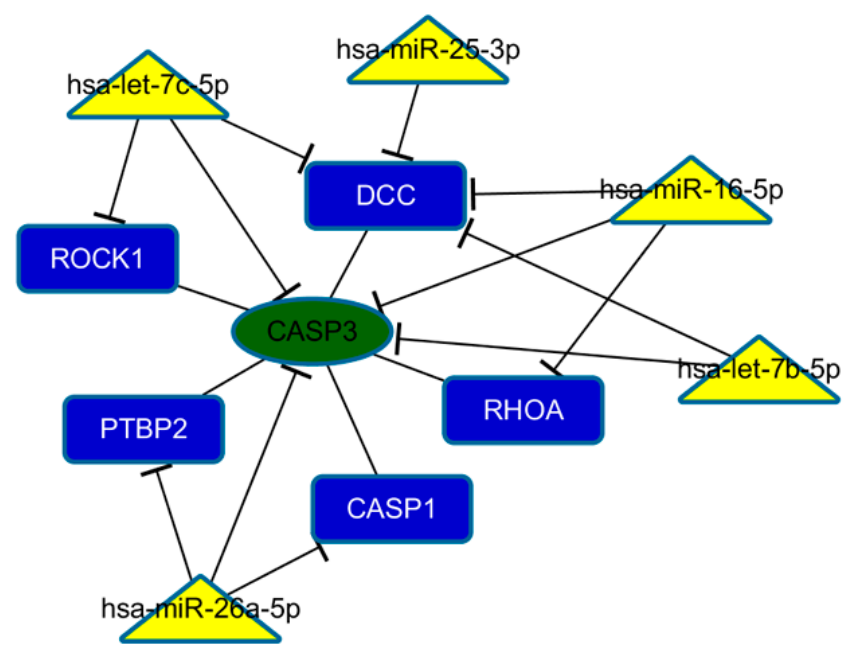

Figure 5. Cont. 
E

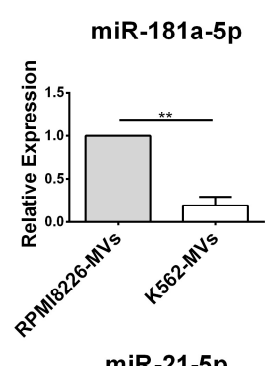

miR-21-5p

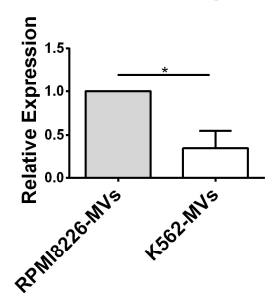

miR-92a-1-5p

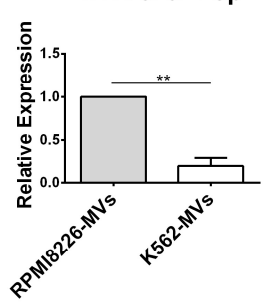

miR-18a-5p

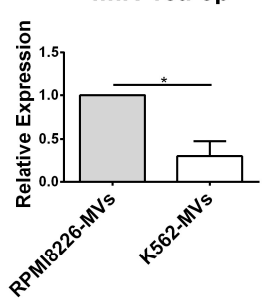

miR-19a-3p

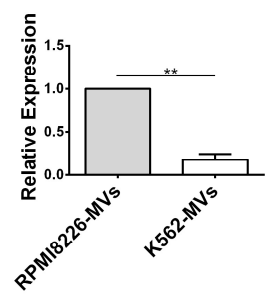

miR-16-5p

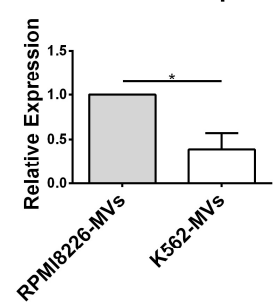

miR-21-3p

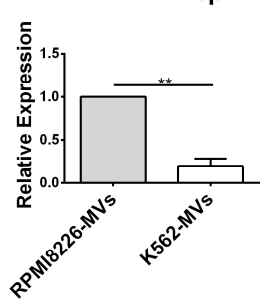

miR-25-3p

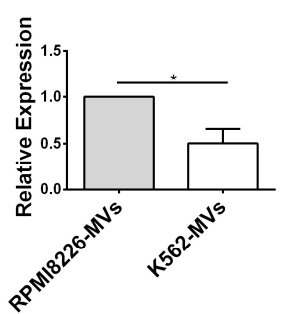

Figure 5. Selective miRNAs in MM-MVs that confer caspase-3-induced apoptosis in HK-2 cells. (A) Comparative analysis of renal-pathogenic miRNAs between RPMI8226-MVs and K562-MVs. RPMI8226-MVs were enriched in more highly-expressed renal-pathogenic miRNAs than did K562-MVs; (B) The heatmap of renal-protective miRNAs in RPMI8226-MVs and K562-MVs showed low levels of renal-protective miRNAs in the two types of MVs; (C,D) A schematic illustration representing MM-MV-packed miRNAs, including renal-pathogenic (C) and -protective miRNAs (D), and potential targets involved in regulation of caspase-3 in HK-2 cells. Yellow triangles: miRNAs relatively highly represented in RPMI8226-MVs. Green ellipse: caspase 3 gene. Blue rectangles: regulators interacted with hub genes and targeted by miRNAs; (E) Evaluation of the levels of the miRNAs involved in the regulation network and differentially expressed between RPMI8226-MVs and K562-MVs, using real-time PCR $\left({ }^{*} p<0.01,{ }^{* *} p<0.05\right)$.

Based on the induced expression of cleaved caspase-3 protein in the MM-MV-treated HK-2 cells, we further analyzed miRNAs in MM-MVs targeting caspase-3. We used collected RI-associated pathogenic and protective miRNAs to construct a caspase-3 regulating network. We found five important genes (RHOA, DCC, CASP1, PTBP2, and ROCK1) interact with caspase-3 directly. In the pathogenic miRNAs caspase-3 network (Figure 5C), 16 miRNAs contribute to the caspase-3 regulatory network, six miRNAs (hsa-miR-382-5p, hsa-miR-17-3p, hsa-miR-20a-3p, hsa-miR-26a-5p, hsa-miR-22-5p, and hsa-miR-19a-3p) repress caspase-3 directly, and the rest of the miRNAs regulate five other genes to affect caspase-3 indirectly. Similarly in Figure 4D, four protective miRNAs interact with caspase-3 directly. There are more pathogenic miRNAs than protective miRNAs contributing to regulate caspase-3. Furthermore, we evaluated the levels of the miRNAs that were involved in the regulation of caspase-3 and differentially expressed between RPMI8226-MVs and K562-MVs, using single assay real-time PCR (Figure 5E).

Though the other activated apoptosis regulators were not similarly investigated, these findings demonstrate that RI-associated miRNAs are selectively enriched in MM-MVs and might contribute to the induced apoptosis in the HK-2 cells by MM-MVs.

\subsection{CD138+Circulating MV (cirMV) Counts Positively Correlate with Renal Impairment}

Due to the effects of MM-MVs on HK-2 cells, we further investigated the clinical significance of MM-MVs in patients with MM. In this study, we enrolled 61 de novo patients with MM (Table 1), and circulating MVs (cirMVs) in the peripheral blood were analyzed using a BD LSR II flow cytometer (BD Biosciences, San Jose, CA, USA) equipped with FACSDiva software. Based on the phenotypic characteristics of MM-MVs and the findings by Krishnan and collegues [23], we used CD138+ cirMVs 
to represent circulating MM-MVs in patients with MM. Meanwhile, according to the serum creatinine levels ( $\mathrm{SCr}$ ), the patients were classified into two groups (group 1, $\mathrm{SCr}<2 \mathrm{mg} / \mathrm{dL}, n=45$; group 2, $\mathrm{SCr} \geq 2 \mathrm{mg} / \mathrm{dL}, n=16)$. We assayed the association between RI and CD138+ cirMV counts in the two groups. We found that CD138+ cirMV counts were significantly higher in group 1 than in group 2 $(p=0.0138)$, and the ROC value for using CD138+ cirMV counts to diagnose RI in de novo patients with MM was 0.731 (Figure 6). These findings support that CD138+ cirMV counts play a role in the diagnosis of RI in de novo MM patients.

Table 1. Clinical characteristics of patients with de novo multiple myeloma (MM).

\begin{tabular}{|c|c|}
\hline Clinical Characteristics & Patient Number (n) \\
\hline Total & 61 \\
\hline \multicolumn{2}{|l|}{ Sex } \\
\hline Male & 40 \\
\hline Female & 21 \\
\hline Median age, years (range) & $59(40-82)$ \\
\hline \multicolumn{2}{|l|}{ Durie-Salmon stage } \\
\hline $\mathrm{I}$ & 3 \\
\hline II & 11 \\
\hline III & 38 \\
\hline \multicolumn{2}{|l|}{ International staging system } \\
\hline $\mathrm{I}$ & 6 \\
\hline II & 25 \\
\hline III & 27 \\
\hline \multicolumn{2}{|l|}{ Type of monoclonal Ig } \\
\hline IgG & 27 \\
\hline $\operatorname{Ig} A$ & 16 \\
\hline $\operatorname{IgD}$ & 3 \\
\hline $\mathrm{LC}^{\mathrm{a}}$ only & 8 \\
\hline \multicolumn{2}{|l|}{ Renal function } \\
\hline Group $1(\mathrm{SCr} b<2 \mathrm{mg} / \mathrm{dL})$ & 45 \\
\hline Group $2(\mathrm{SCr} \geq 2 \mathrm{mg} / \mathrm{dL})$ & 16 \\
\hline
\end{tabular}

${ }^{\mathrm{a}}$ LC, light chain; ${ }^{\mathrm{b}} \mathrm{SCr}$ : serum creatinine.

A

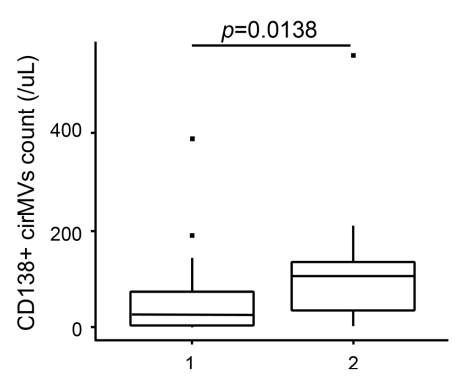

B

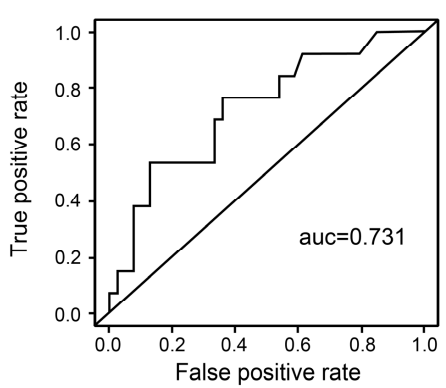

Figure 6. CD138+ cirMV counts positively correlate with renal impairment. The enrolled 61 de novo patients with MM were divided into two groups according the levels of $\mathrm{SCr}$ (group 1, $\mathrm{SCr}<2 \mathrm{mg} / \mathrm{dL}$, $n=45$; group $2 \mathrm{SCr} \geq 2 \mathrm{mg} / \mathrm{dL}, n=16$ ). The levels of CD138+ cirMVs were significantly higher in group 1 than in group $2(\mathbf{A}, p=0.0138)$, and the ROC value for using CD138+ cirMV counts to diagnose $\mathrm{RI}$ in de novo patients with MM was 0.731 (B). 


\section{Discussion}

Mayo Clinic [24] reported that both Ig-relevant and Ig-irrelevant damage exist in MM-associated RI, the underlying mechanisms remain elusive. Here, our data demonstrate that MM-MVs significantly inhibit viability and induce apoptosis, but not EMT in HK-2 cells, and our analysis of the signature of miRNA repertoires in MM-MVs support the miRNA content might potentially contribute to these effects. Furthermore, we confirmed the clinical significance of peripheral circulating CD138+ cirMV counts in RI in de novo MM patients. To the best of our knowledge, this is the first study to investigate the role of MM-MVs in myeloma RI.

MiRNAs are small noncoding RNAs (19-24 nucleotides in length) that down-regulate gene expression at the post-transcriptional level, and play crucial roles in diverse physiological processes and certain miRNAs have been demonstrated involving in kidney physiology and pathophysiology [25]. MV-mediated transfer of miRNAs, as a degrading enzyme-protective way, has been verified in various contexts. For example, recent reports have demonstrated that miRNAs carried by MSC-MVs can facilitate renal recovery from acute kidney injury [26,27]. Here, small RNA sequencing analysis of MVs exhibited that renal-pathogenic miRNAs were more abundant in RPMI8226-MVs than K562-MVs. In particular, miR-21 [28], miR-181 [29], and miR-20 [30] had been demonstrated as key regulators in pathological processing of renal disease. On the contrary, renal-protective miRNAs were expressed at low levels in RPMI8226-MVs. Thus, we considered the aberrant expression of renal-disease related miRNAs in MM-MVs might contribute to the adverse effects on HK-2 cells. The exact roles of the specific miRNA or all of the miRNAs are to be investigated.

Our in vitro study demonstrates that RPMI8226-MVs and U266-MVs inhibited viability in HK-2 cells, in large part due to the enhanced cell apoptosis. However, the viability in the untreated HK-2 cells showed mild changes within the three days of culture, which might be due to the high cell density, and the inhibitory effect of MM-MVs on HK-2 viability seemed to reach the utmost limit at $72 \mathrm{~h}$, which implies that MM-MVs should be added more than once, or there are unknown mechanisms underlying the resistance. It is known that caspase-8/9 are important initiators for extrinsic and intrinsic apoptosis. In these two kinds of apoptosis, the cleaved caspases mediated the activation of caspase-3, which is a critical executive molecule in apoptosis and has been demonstrated and applied regularly in apoptosis detection [31]. Our results showed that the caspase-3/8/9 were activated either by increasing the MM-MV concentration or prolonging the incubation time, suggesting that MM-MVs accelerate apoptosis, possibly via caspase signaling in HK-2 cells. Actually, the results confirmed that Bcl-2 family members were involved, with the up-regulated expression of pro-apototic regulators of Bim and Bid, and the down-regulated expression of anti-apototic regulators of Bcl-xl and Bcl-2. As MV-shuttled miRNAs are complex populations we considered, instead of a single miRNA determinant, that the complicated interactions of the molecular landscape contribute to the function of MM-MVs, which had been shown in the miRNA regulation networks. To be noted, our clinical data of 61 de novo patients demonstrate that CD138+ cirMV counts were positively correlated with the severity of renal impairment, suggesting of the potential role of MM-MVs as a driver biomarker in the development and diagnosis of RI of MM patients. It is certainly critical to directly assay the effect of primary MM-MVs from MM patients on HK-2 viability and apoptosis, and to deeply study their miRNA content. However, because of the difficulties in isolating and purifying enough CD138+ cirMVs from the limited volume of peripheral blood, we failed to present these data here. In addition, the functions, signaling pathways, and critical determinants variations in recipient cells underlying our findings are also challenges promising to be solved in the future.

\section{Materials and Methods}

\subsection{Cell Culture}

Human RPMI8226 and U266 MM cell lines (purchased from American Type Culture Collection, ATCC, Rockefeller, MD, USA), human chronic myeloid leukemia cell line K562 (routinely preserved in 
our laboratory), and human renal tubular epithelial cell line, HK-2 cells (purchased from Guangzhou Jennio Biological Technology, Guangzhou, China) were cultured in RPMI-1640 containing 10\% fetal bovine serum (FBS; Hyclone, South Logan, UT, USA), and 1\% penicillin-streptomycin (Beyotime, Shanghai, China) at $37^{\circ} \mathrm{C}$ in a $5 \% \mathrm{CO}_{2}$ humidified atmosphere.

\subsection{Isolation and Quantification}

MVs were isolated by differential ultracentrifugation as we described previously [11,14]. Briefly, harvested cell culture medium was centrifuged at $750 \times g$ for $15 \mathrm{~min}$ and $1500 \times g$ for $20 \mathrm{~min}$ to remove cells debris. Then MVs were pelleted. The supernatant was discarded and the MV pellet was washed and resuspended in PBS, followed by another centrifugation at $16,000 \times g$ for $1 \mathrm{~h}$ at $4{ }^{\circ} \mathrm{C}$. The quantity of MVs was determined by measuring the total protein content through the BCA protein assay kit (Beyotime, Shanghai, China). The MVs were prepared before use.

\subsection{Transmission Electron Microscopy (TEM) and Scanning Electron Microscopy (SEM)}

TEM (FEI, Hillsboro, OR, USA) was conducted as per our published papers [14]. MM-MVs were also observed by SEM (FEI, Hillsboro, OR, USA). Poly lysine coated coverslip preparation, cell fixation, dehydration, drying, and coating were performed as per the regular protocol [32]. Images were captured with a scanning electron microscope (Tescan, Brno, Czech Republic).

\subsection{Small RNA Sequencing and Data Analyses}

Total RNA of RPMI8226-MVs was used to generate a small RNA sequencing library using reagents and methods provided with TruSeq Small RNA Sample Prep Kit (Illumina, San Diego, CA, USA) and sequenced by IlluminaHiSeq. The K562-MVs small RNA-seq data were from our previous findings [33]. The FASTQ files of the RNA-Seq and small RNA-Seq data of RPMI8226-MVs and K562-MVs were submitted to the NCBI Sequence Read Archive (SRA) under accession numbers SRP092289 and SRP057826, respectively. We trimmed the $5^{\prime}$ and $3^{\prime}$ adapters, filtered the low-quality reads, and kept the 18 30 nt reads. The reads were mapped to hg19 with BWA [34]. The remaining reads were mapped to human pre-miRNA miRBase release 20 [35] with miRExpress 2.0 [36]. The expression level of miRNA was normalized with RPM (reads per million mapped reads).

\subsection{Cell Viability Detection}

The viability analysis of HK-2 Cells treated by MM-MVs was performed by Cell Counting Kit- 8 (CCK-8, Guangzhou Yiyuan Biotech. Co., Ltd., Gunagzhou, China). HK-2 cells were incubated with various MVs (RPMI 8226, U266, and K562-MVs) at a range of concentrations (0, 1, 5, 10, and $50 \mu \mathrm{g} / \mathrm{mL}$ ) for different times $(24,48$, or $72 \mathrm{~h}$ ). Incubation accomplished, the fresh CCK working liquid (dilution 1:10) was added and incubated for $2.5 \mathrm{~h}$. The absorbance value was determined at $450 \mathrm{~nm}$ using a microplate reader.

\subsection{Apoptosis Detection}

Cell apoptosis rate was measured by flow cytometry (FCM) using the Annexin V-PI Apoptosis Detection Kit (Beyotime, Shanghai, China). HK-2 cells were placed at $1 \times 10^{5} / \mathrm{mL}$ in triplicate. In $24 \mathrm{~h}$, culture media was discarded and cells were resuspended with MV suspension at different concentration. For the medium groups, HK-2 cells were incubated in six-well plates with $100 \mu \mathrm{L} /$ well cultured medium of MM cells, with or without the depletion of MVs. The treated HK-2 cells were cultured for 48 or $72 \mathrm{~h}$, then an Annexin V-PI apoptosis detection kit was used according to the manufacturer's instructions. Afterwards, the apoptosis analysis was conducted using a FACSAria II (BD Pharmingen, San Diego, CA, USA). 


\subsection{Western Blotting}

HK-2 cells were treated with $10 \mu \mathrm{g} / \mathrm{mL}$ MVs of various cell types and collected at 48 and $72 \mathrm{~h}$. Then, cells were solubilized in sodium dodecyl sulfate lysis buffer. Protein samples were separated by sodium dodecyl sulfate polyacrylamide gel electrophoresis (SDS-PAGE), transferred onto a phenylmethylsulfonyl fluoride (PVDF) membrane, and incubated with the primary rabbit anti-human total caspase-3, cleaved caspase-3, total caspase-8, cleaved caspase-3, total caspase-9, cleaved caspase-9, Bim, Bcl-xl, Bid, cleaved Bid, Bcl-2, E-cadherin, Vimentin, and GAPDH antibodies (Sigma-Aldrich, St Louis, MO, USA) at $4{ }^{\circ} \mathrm{C}$. After washing with TBS-T five or six times, the membranes were then probed with horseradish peroxidase (HRP)-conjugated secondary goat anti-rabbit antibody (Wuhan Boster Biotechnology Co., Ltd., Wuhan, China) for $2 \mathrm{~h}$ at room temperature. Enhanced chemiluminescence was performed according to the manufacturer's instructions (Beyotime, Shanghai, China). All the experiments were repeated in triplicate.

\subsection{Immunofluorescent Stainning}

After treatment of MVs $(10 \mu \mathrm{g})$ for $72 \mathrm{~h}, \mathrm{HK}-2$ cells were cultured on sterile glass coverslips and fixed in $4 \%$ paraformaldehyde for $30 \mathrm{~min}$. After washing with PBS three times, the coverslips were permeabilized with $0.1 \%$ Triton X-100 for $5 \mathrm{~min}$, blocked in 5\% bovine serum albumin (BSA), and then incubated with the primary antibodies (anti-E-cadherin and anti-vimentin, TDY, Beijing, China) at $4{ }^{\circ} \mathrm{C}$ overnight. The slips were next washed and incubated with $\mathrm{Cy}$-3-conjugated goat anti-mouse or anti-rabbit secondary IgG (Proteintech Group, Rosemont, IL, USA) at room temperature for $1 \mathrm{~h}$. Cells were observed using a Nikon (Melvile, NY, USA) Eclipse TE300 fluorescence microscope.

\subsection{Construction of miRNA Regulatory Network}

Known miRNAs related to renal disease are important for uncovering the co-regulation of the renal disease. We collected valid miRNAs in renal disease through reviewing peer-reviewed publications. We screened differentially-expressed miRNA from known miRNAs datasets labeled as "pathogenic" and "protective", and obtained their predicted targets by the Targetscan [37] and miRanda [38]. Genes and candidate miRNAs were constructed regulating network by Cytoscape [39].

\subsection{Realtime PCR}

We used Trizol reagent (Invitrogen, Waltham, MA, USA) to isolate total RNA from RPMI8226-MVs and K562-MVs according to the manufacturer's instructions. RNA quality and purity were determined by a nucleic acid/protein analyzer (Beckman Coulter, Brea, CA, USA), with the $A_{260} / A_{280}$ ratio values ranging from 1.8 to 2.0. Reverse transcription was performed by the FastQuant RT Kit (TIANGEN, Beijing, China), and then the real-time reverse transcriptase polymerase chain reaction (RT-PCR) was conducted with the SYBR green PCR master mix (TIANGEN) on an Applied Biosystems 7500 Real-Time PCR System. Each reaction was performed in triplicate and normalized to U6. Relative expression levels of miRNA were expressed through the $\Delta \Delta C_{\mathrm{t}}$ method.

\subsection{Clinical Samples Collection}

The peripheral blood (PB) of MM patients was obtained in anti-coagulate tubes with ethylenediaminetetraacetic acid (EDTA) anticoagulant, which has been considered more appropriate than heparin for MV detection by flow cytometry in our previous study [40]. All MM patients were from Institute of Hematology, Union Hospital, Tongji Medical College, Huazhong University of Science and Technology. This study was approved by the Review Board of Tongji Medical College (No. 2012S119, 6 March 2012) and informed consent was obtained from each volunteer. The EDTA-anticoagulated blood was double centrifuged at $2500 \times g$ for $30 \mathrm{~min}$ at $20^{\circ} \mathrm{C}$. Platelet-free plasma was obtained and then centrifuged at $16,000 \times g$ for $15 \mathrm{~min}$ at $20^{\circ} \mathrm{C}$ to harvest cirMVs. 


\subsection{Quantitative Detection of cirMVs}

The detailed protocol of MVs enumeration by FCM has been stated in our previous reports [40]. We defined MM-cirMVs as CD138+Calcein-AM+vesicles with a diameter of less than $1 \mu \mathrm{m}$. The cirMVs preparation was resuspended by PBS, and then stained with calcein-AM and CD138-PE. After incubation for $30 \mathrm{~min}$ at $4{ }^{\circ} \mathrm{C}$, cirMVs were washed with PBS at $16,000 \times g$ for $15 \mathrm{~min}$ and resuspended for examination by a FACSAria II (BD Pharmingen, San Diego, CA, USA).

\subsection{Statistical Analysis}

GraphPad Prism version 6.0 (GraphPad Software, GraphPad Software Inc, California, KY, USA) and $\mathrm{R}$ version 3.2.2 were used for all calculations and figures. Nonparametric and unpaired $t$-tests were used to compare groups. The Wilcoxon rank test was used for comparisons of cirEV counts between the two groups of patients with MM. ROC curves were used to determine the sensitivity, specificity, and positive and negative predictive values. All presented $p$-values are two-sided, and $p<0.05$ was considered to indicate statistical significance.

\section{Conclusions}

In conclusion, this primary study supported MM-MVs to represent a previously undescribed factor and play a potential role in the development of the characteristic renal lesion in kidney damage of MM patients. Our study sheds light on the potential application of CD138+cirMV counts in precise diagnosis of RI in MM and exploring MM-MVs as a therapeutic target.

Supplementary Materials: Supplementary materials can be found at www.mdpi.com/1422-0067/18/3/513/s1.

Acknowledgments: The authors thank Yong $\mathrm{Xu}$ and Zhihui Liang from the Institute of Biochemistry (School of Basic Medicine, Huazhong University of Science and Technology) for their assistance in FCM detection and data analysis. This work was supported by grants from the National Nature Science Foundation of China (NSFC; 81071943 and 81272624 to Qiubai Li, and 81170497 to Zhichao Chen.

Author Contributions: Qiubai Li and Zhichao Chen designed the study. Aiqi Zhao and Fancong Kong contributed equally to this work and performed the majority of experiments, data collection, and analysis. Chun-Jie Liu, Guoxin Yan, Fei Gao, Hao Guo, and An-Yuan Guo performed experiments and collected clinical samples. Qiubai Li and Aiqi Zhao wrote the manuscript and assisted in the final approval of the manuscript.

Conflicts of Interest: The authors declare no conflict of interest.

\section{Abbreviations}

$\begin{array}{ll}\text { RI } & \text { Renal Impairment } \\ \text { MM } & \text { Multiple Myeloma } \\ \text { MVs } & \text { Microvesicles } \\ \text { EMT } & \text { Epithelial-Mesenchymal Transition } \\ \text { RPM } & \text { Reads Per Million Mapped Reads }\end{array}$

\section{References}

1. Dimopoulos, M.A.; Terpos, E.; Chanan-Khan, A.; Leung, N.; Ludwig, H.; Jagannath, S.; Niesvizky, R.; Giralt, S.; Fermand, J.P.; Blade, J.; et al. Renal impairment in patients with multiple myeloma: A consensus statement on behalf of the international myeloma working group. J. Clin. Oncol. 2010, 28, 4976-4984. [CrossRef] [PubMed]

2. Knudsen, L.M.; Hippe, E.; Hjorth, M.; Holmberg, E.; Westin, J. Renal function in newly diagnosed multiple myeloma-A demographic study of 1353 patients. The nordic myeloma study group. Eur. J. Haematol. 1994, 53, 207-212. [CrossRef] [PubMed]

3. Yadav, P.; Cook, M.; Cockwell, P. Current trends of renal impairment in multiple myeloma. Kidney Dis. 2016, 1, 241-257. [CrossRef] 
4. Kyle, R.A.; Gertz, M.A.; Witzig, T.E.; Lust, J.A.; Lacy, M.Q.; Dispenzieri, A.; Fonseca, R.; Rajkumar, S.V.; Offord, J.R.; Larson, D.R.; et al. Review of 1027 patients with newly diagnosed multiple myeloma. Mayo Clin. Proc. 2003, 78, 21-33. [CrossRef] [PubMed]

5. Nordentoft, M. Prevention of suicide and attempted suicide in denmark. Epidemiological studies of suicide and intervention studies in selected risk groups. Dan. Med. Bull. 2007, 54, 306-369. [PubMed]

6. Eleutherakis-Papaiakovou, V.; Bamias, A.; Gika, D.; Simeonidis, A.; Pouli, A.; Anagnostopoulos, A.; Michali, E.; Economopoulos, T.; Zervas, K.; Dimopoulos, M.A.; et al. Renal failure in multiple myeloma: Incidence, correlations, and prognostic significance. Leuk. Lymphoma 2007, 48, 337-341. [CrossRef] [PubMed]

7. Heher, E.C.; Rennke, H.G.; Laubach, J.P.; Richardson, P.G. Kidney disease and multiple myeloma. Clin. J. Am. Soc. Nephrol. 2013, 8, 2007-2017. [CrossRef] [PubMed]

8. Kastritis, E.; Zervas, K.; Symeonidis, A.; Terpos, E.; Delimbassi, S.; Anagnostopoulos, N.; Michali, E.; Zomas, A.; Katodritou, E.; Gika, D.; et al. Improved survival of patients with multiple myeloma after the introduction of novel agents and the applicability of the international staging system (ISS): An analysis of the greek myeloma study group (GMSG). Leukemia 2009, 23, 1152-1157. [CrossRef] [PubMed]

9. Tkach, M.; Thery, C. Communication by extracellular vesicles: Where we are and where we need to go. Cell 2016, 164, 1226-1232. [CrossRef] [PubMed]

10. Van der Pol, E.; Boing, A.N.; Harrison, P.; Sturk, A.; Nieuwland, R. Classification, functions, and clinical relevance of extracellular vesicles. Pharmacol. Rev. 2012, 64, 676-705. [CrossRef] [PubMed]

11. Liu, Y.; Zhu, X.J.; Zeng, C.; Wu, P.H.; Wang, H.X.; Chen, Z.C.; Li, Q.B. Microvesicles secreted from human multiple myeloma cells promote angiogenesis. Acta Pharmacol. Sin. 2014, 35, 230-238. [CrossRef] [PubMed]

12. Zhu, X.; You, Y.; Li, Q.; Zeng, C.; Fu, F.; Guo, A.; Zhang, H.; Zou, P.; Zhong, Z.; Wang, H.; et al. Bcr-abl1-positive microvesicles transform normal hematopoietic transplants through genomic instability: Implications for donor cell leukemia. Leukemia 2014, 28, 1666-1675. [CrossRef] [PubMed]

13. Yamada, N.; Tsujimura, N.; Kumazaki, M.; Shinohara, H.; Taniguchi, K.; Nakagawa, Y.; Naoe, T.; Akao, Y. Colorectal cancer cell-derived microvesicles containing microrna-1246 promote angiogenesis by activating smad 1/5/8 signaling elicited by pml down-regulation in endothelial cells. Biochim. Biophys. Acta 2014, 1839, 1256-1272. [CrossRef] [PubMed]

14. Sun, L.; Wang, H.X.; Zhu, X.J.; Wu, P.H.; Chen, W.Q.; Zou, P.; Li, Q.B.; Chen, Z.C. Serum deprivation elevates the levels of microvesicles with different size distributions and selectively enriched proteins in human myeloma cells in vitro. Acta Pharmacol. Sin. 2014, 35, 381-393. [CrossRef] [PubMed]

15. Li, M.; Hering-Smith, K.S.; Simon, E.E.; Batuman, V. Myeloma light chains induce epithelial-mesenchymal transition in human renal proximal tubule epithelial cells. Nephrol. Dial. Transplant. 2008, 23, 860-870. [CrossRef] [PubMed]

16. Chen, X.; Liang, H.; Zhang, J.; Zen, K.; Zhang, C.Y. Secreted micrornas: A new form of intercellular communication. Trends Cell Biol. 2012, 22, 125-132. [CrossRef] [PubMed]

17. Pavkovic, M.; Vaidya, V.S. MicroRNAs and drug-induced kidney injury. Pharmacol. Ther. 2016, 163, 48-57. [CrossRef] [PubMed]

18. Trionfini, P.; Benigni, A.; Remuzzi, G. Micrornas in kidney physiology and disease. Nat. Rev. Nephrol. 2015, 11, 23-33. [CrossRef] [PubMed]

19. Lee, C.G.; Kim, J.G.; Kim, H.J.; Kwon, H.K.; Cho, I.J.; Choi, D.W.; Lee, W.H.; Kim, W.D.; Hwang, S.J.; Choi, S.; et al. Discovery of an integrative network of micrornas and transcriptomics changes for acute kidney injury. Kidney Int. 2014, 86, 943-953. [CrossRef] [PubMed]

20. Serino, G.; Sallustio, F.; Curci, C.; Cox, S.N.; Pesce, F.; de Palma, G.; Schena, F.P. Role of let-7b in the regulation of n-acetylgalactosaminyltransferase 2 in iga nephropathy. Nephrol. Dial. Transplant. 2015, 30, 1132-1139. [CrossRef] [PubMed]

21. Chen, H.H.; Lan, Y.F.; Li, H.F.; Cheng, C.F.; Lai, P.F.; Li, W.H.; Lin, H. Urinary mir-16 transactivated by $\mathrm{C} / \mathrm{EBP} \beta$ reduces kidney function after ischemia/reperfusion-induced injury. Sci. Rep. 2016, 6, 27945. [CrossRef] [PubMed]

22. Rudnicki, M.; Beckers, A.; Neuwirt, H.; Vandesompele, J. RNA expression signatures and posttranscriptional regulation in diabetic nephropathy. Nephrol. Dial. Transplant. 2015, 30, iv35-iv42. [CrossRef] [PubMed]

23. Krishnan, S.R.; Luk, F.; Brown, R.D.; Suen, H.; Kwan, Y.; Bebawy, M. Isolation of human CD138+ microparticles from the plasma of patients with multiple myeloma. Neoplasia 2016, 18, 25-32. [CrossRef] [PubMed] 
24. Nasr, S.H.; Valeri, A.M.; Sethi, S.; Fidler, M.E.; Cornell, L.D.; Gertz, M.A.; Lacy, M.; Dispenzieri, A.; Rajkumar, S.V.; Kyle, R.A.; et al. Clinicopathologic correlations in multiple myeloma: A case series of 190 patients with kidney biopsies. Am. J. Kidney Dis. 2012, 59, 786-794. [CrossRef] [PubMed]

25. Heher, E.C.; Goes, N.B.; Spitzer, T.R.; Raje, N.S.; Humphreys, B.D.; Anderson, K.C.; Richardson, P.G. Kidney disease associated with plasma cell dyscrasias. Blood 2010, 116, 1397-1404. [CrossRef] [PubMed]

26. Collino, F.; Bruno, S.; Incarnato, D.; Dettori, D.; Neri, F.; Provero, P.; Pomatto, M.; Oliviero, S.; Tetta, C.; Quesenberry, P.J.; et al. Aki recovery induced by mesenchymal stromal cell-derived extracellular vesicles carrying microRNAs. J. Am. Soc. Nephrol. 2015, 26, 2349-2360. [CrossRef] [PubMed]

27. Zhou, Y.; Xu, H.; Xu, W.; Wang, B.; Wu, H.; Tao, Y.; Zhang, B.; Wang, M.; Mao, F.; Yan, Y.; et al. Exosomes released by human umbilical cord mesenchymal stem cells protect against cisplatin-induced renal oxidative stress and apoptosis in vivo and in vitro. Stem Cell Res. Ther. 2013, 4, 34. [CrossRef] [PubMed]

28. Jia, P.; Teng, J.; Zou, J.; Fang, Y.; Wu, X.; Liang, M.; Ding, X. Xenon protects against septic acute kidney injury via mir-21 target signaling pathway. Crit. Care Med. 2015, 43, e250-e259. [CrossRef] [PubMed]

29. Belkaya, S.; Silge, R.L.; Hoover, A.R.; Medeiros, J.J.; Eitson, J.L.; Becker, A.M.; de la Morena, M.T.; Bassel-Duby, R.S.; van Oers, N.S. Dynamic modulation of thymic microRNAs in response to stress. PLoS ONE 2011, 6, e27580. [CrossRef] [PubMed]

30. Marrone, A.K.; Stolz, D.B.; Bastacky, S.I.; Kostka, D.; Bodnar, A.J.; Ho, J. MicroRNA-17 92 is required for nephrogenesis and renal function. J. Am. Soc. Nephrol. 2014, 25, 1440-1452. [CrossRef] [PubMed]

31. Thornberry, N.A.; Lazebnik, Y. Caspases: Enemies within. Science 1998, 281, 1312-1316. [CrossRef] [PubMed]

32. Mrvar-Brecko, A.; Sustar, V.; Jansa, V.; Stukelj, R.; Jansa, R.; Mujagic, E.; Kruljc, P.; Iglic, A.; Hagerstrand, H.; Kralj-Iglic, V. Isolated microvesicles from peripheral blood and body fluids as observed by scanning electron microscope. Blood Cells Mol. Dis. 2010, 44, 307-312. [CrossRef] [PubMed]

33. Zhang, H.M.; Li, Q.; Zhu, X.; Liu, W.; Hu, H.; Liu, T.; Cheng, F.; You, Y.; Zhong, Z.; Zou, P.; et al. Mir-146b-5p within bcr-abl1-positive microvesicles promotes leukemic transformation of hematopoietic cells. Cancer Res. 2016, 76, 2901-2911. [CrossRef] [PubMed]

34. Li, H.; Durbin, R. Fast and accurate short read alignment with burrows-wheeler transform. Bioinformatics 2009, 25, 1754-1760. [CrossRef] [PubMed]

35. Kozomara, A.; Griffiths-Jones, S. Mirbase: Annotating high confidence micrornas using deep sequencing data. Nucleic Acids Res. 2014, 42, D68-D73. [CrossRef] [PubMed]

36. Wang, W.C.; Lin, F.M.; Chang, W.C.; Lin, K.Y.; Huang, H.D.; Lin, N.S. Mirexpress: Analyzing high-throughput sequencing data for profiling microRNA expression. BMC Bioinform. 2009, 10, 328. [CrossRef] [PubMed]

37. Agarwal, V.; Bell, G.W.; Nam, J.W.; Bartel, D.P. Predicting effective microRNA target sites in mammalian mrnas. eLife 2015, 4, e05005. [CrossRef] [PubMed]

38. Betel, D.; Wilson, M.; Gabow, A.; Marks, D.S.; Sander, C. The microRNA.Org resource: Targets and expression. Nucleic Acids Res. 2008, 36, D149-D153. [CrossRef] [PubMed]

39. Shannon, P.; Markiel, A.; Ozier, O.; Baliga, N.S.; Wang, J.T.; Ramage, D.; Amin, N.; Schwikowski, B.; Ideker, T. Cytoscape: A software environment for integrated models of biomolecular interaction networks. Genome Res. 2003, 13, 2498-2504. [CrossRef] [PubMed]

40. Kong, F.; Zhang, L.; Wang, H.; Yuan, G.; Guo, A.; Li, Q.; Chen, Z. Impact of collection, isolation and storage methodology of circulating microvesicles on flow cytometric analysis. Exp. Ther. Med. 2015, 10, 2093-2101. [CrossRef] [PubMed]

(c) 2017 by the authors. Licensee MDPI, Basel, Switzerland. This article is an open access article distributed under the terms and conditions of the Creative Commons Attribution (CC BY) license (http:/ / creativecommons.org/licenses/by/4.0/). 